\title{
FORMAR BEM AS MÃES PARA CRIAR E EDUCAR BOAS CRIANÇAS: AS REVISTAS PORTUGUESAS DE EDUCAÇÃO FAMILIAR E A DIFUSÃO DA MATERNIDADE CIENTÍFICA (1945-1958)
}

\author{
Carla Cardoso Vilhena \\ Universidade do Algarve, Portugal. \\ António Gomes Ferreira \\ Universidade de Coimbra, Portugal.
}

$\cos 80$

\begin{abstract}
Resumo
Este artigo tem como principal objetivo contribuir para a compreensão do processo de construção da maternidade científica em Portugal. Neste sentido, foi analisado um conjunto de artigos $(n=628)$, publicados em revistas de educação familiar, entre 1945 e 1958. A análise realizada permitiu compreender que as revistas analisadas contribuem para a difusão da maternidade científica, ou seja, da ideia de que a aquisição de conhecimento científico sobre a criação e educação das crianças é elemento indispensável ao adequado exercício da função maternal. Observou-se, ainda, a existência de diferentes estratégias de educação para a maternidade, às quais está subjacente um elemento de classe, assim como diferentes níveis de adesão, por parte das mulheres, à concepção de maternidade científica.
\end{abstract}

Palavras-chave: maternidade científica, educação para a maternidade, revistas de educação familiar, análise de discurso.

\section{EDUCATE MOTHERS TO REAR AND EDUCATE GOOD CHILDREN: PORTUGUESE PARENTING MAGAZINES AND THE DIFFUSION OF SCIENTIFIC MOTHERHOOD (1945-1958)}

\section{Abstract}

This article explores the construction of scientific motherhood in Portugal through the analysis of a set of texts on education for motherhood $(n=628)$ published in Portuguese parenting magazines between 1945 and 1958. Our results show that the diffusion of a particular view of the ideal mother in parenting magazines contributes to the diffusion of a new ideology that stresses the importance of education for motherhood, the ideology of scientific motherhood. It also shows the emergence of 
different types of educational interventions, shaped by women's social class, and provides some insight into the extent to which mothers adhere to scientific motherhood.

Keywords: scientific motherhood, education for motherhood, parenting magazines, discourse analysis.

\section{FORMAR BIEN LAS MADRES PARA CREAR Y EDUCAR NIÑOS BUENOS: LAS REVISTAS PORTUGUÉS PARA PADRES Y LA DIFUSIÓN DE LA MATERNIDAD CIENTÍFICA (1945-1958)}

\section{Resumen}

Este artículo tiene como objetivo principal contribuir a la comprensión de la construcción de la maternidad científica en Portugal. En este sentido, se analizó un conjunto de artículos ( $n=628)$, publicado en revistas para padres entre 1945 y 1958. El análisis permitió entender que las revistas analizadas contribuyen a la difusión de la maternidad científica, es decir, a la idea de que la adquisición de conocimientos científicos acerca de la formación y educación de los niños es imprescindible para el ejercicio adecuado de la función maternal. Igualmente se observó la existencia de distintas estrategias de educación, según la clase social, así como diferentes niveles de afiliación, para las mujeres, à la concepción de la maternidad científica.

Palabras-clave: maternidad científica, educación para la maternidad, revistas para padres, análisis del discurso.

\section{BIEN FORMER DES MÈRES POUR CRÉER ET EDUQUER BONS ENFANTS: MAGASINS PORTUGAIS POUR LES PARENTS ET LA DIFFUSION DE LA MATERNITÉ SCIENTIFIQUE} (1945-1958)

\section{Résumé}

Cet article a comme but de comprendre le processus de construction de la maternité scientifique au Portugal par le biais d'une analyse de 628 articles publiées dans magasins pour les parents entre 1945 et 1958. Les résultats démontrent que les magasins contribuent à la diffusion de la maternité scientifique, c'est l'idée que l'acquisition de connaissances scientifiques sur l'éducation et l'instruction des enfants sont indispensables pour le bon exercice de la fonction maternelle. Nous avons également observé l'existence de différentes stratégies éducatives pour la maternité, déterminée par la classe sociale, ainsi que différents niveaux d'adhésion, chez les femmes, à la conception de la maternité scientifique.

Mots-clé: maternité scientifique, l'éducation des mères, magasins pour les parents, analyse du discours. 


\section{Introdução}

A ética familiar dominante nos anos 1950, no mundo ocidental, reserva à mulher, particularmente a partir do momento em que é mãe, a esfera doméstica (Allen, 2005; Cova; Pinto, 1997; Odland, 2009; Pimentel, 2011; Rocha; Ferreira, 2006). Em Portugal, o reforço da ideologia da domesticidade é acompanhado pela crescente dificultação, por parte do Estado, do acesso das mulheres ao trabalho. É de destacar que as medidas tomadas nesse sentido tiveram algum impacto, uma vez que a taxa de actividade feminina, que se situava em $17 \%$ em 1940 , desce para 13\% em 1950 (Valério, 2001).

A difusão desta ideologia foi realizada por um conjunto de dispositivos e organizações, próprios de uma fase de modernidade organizada (Wagner, 1998), no sentido em que "procuram a modelação cognitiva ou comportamental" (Candeias, 2005, p. 480), ou seja, a modificação dos comportamentos e a consequente adesão das mulheres aos papéis de esposa, mãe e dona de casa, pela educação, considerada um dos mecanismos privilegiados de intervenção no real.

No que diz respeito à realidade portuguesa, as elites do Estado Novo compreenderam bem as potencialidades da educação como mecanismo de socialização, não só ao nível da constituição da escola como um meio de inculcação ideológica, mas utilizando-a para além deste contexto, mediante o reforço de instituições de controlo das famílias (Nóvoa, 1992; Rosas, 2001), criadas ao longo das décadas de 1930 e 1940, tais como a Obra das Mães para a Educação Nacional, o Instituto Maternal ou o Instituto de Assistência à Família, que têm como objectivo comum a regulação e normalização dos comportamentos das mulheres e, através destas, dos restantes membros do agregado familiar.

A preocupação com a educação das mulheres relaciona-se não só com a inculcação de uma determinada ética familiar, mas também com a percepção de que constitui a forma mais eficaz de resolver os principais problemas que atingem as crianças, designadamente a mortalidade e morbilidade infantis. Num contexto em que se assiste a uma maior preocupação com a população, no que diz respeito quer à qualidade, quer à quantidade, as elevadas taxas de mortalidade e morbilidade infantis, tornadas quantificáveis pela aplicação da estatística às questões da população, transformam-se, aos olhos das elites portuguesas, num dos mais graves problemas que afectam a infância (Ferreira, 2003; Ferreira, 2012; Ferreira, M. M. 2000; Pessoa, 2005; Pimentel, 1999).

Apesar da consciência de que fenómenos como a pobreza, a má nutrição ou as más condições de alojamento podem contribuir para este problema, estes são, muitas vezes, ignorados, quer no discurso oficial, quer no discurso dos peritos, sendo atribuída às mães ou, mais concretamente, à sua ignorância no que se refere aos preceitos científicos de criação e educação das crianças, a responsabilidade pela morte das crianças pequenas (Adão; Remédios, 2005; Apple, 2006; Arnup, 1994; Litt, 2000; Martins, 2011).

Paradoxalmente, a valorização do papel da mãe na criação e educação dos seus filhos, e a sua consequente responsabilização pela construção dos futuros cidadãos, é acompanhada por uma crítica à capacidade educativa das mães que, centrando-se, nas primeiras décadas do século 20 , nas mães das classes populares, rapidamente se expande, adquirindo, nos anos 1940, um carácter universal, englobando as mulheres de todas as classes sociais (Vilhena, 2002). Esta crítica tem origem na emergência da 
ideologia da maternidade científica (Apple, 2006), ou seja, na difusão da ideia de que para exercer eficazmente a função maternal as mães têm que conhecer e seguir as regras oriundas das ciências da infância, recorrendo ao auxílio dos peritos.

Tal como demonstraram diversos autores (Apple, 2006; Armstrong, 1995; Ferreira, M. M. 2000; Rose, 1999; Stearns, 2003), a invocação da ignorância das mães constitui um argumento legitimador da intervenção dos peritos junto das mulheres, abrindo-se, assim, caminho para a intervenção dos profissionais da infância - médicos, educadores, psicólogos e psiquiatras - no campo da maternidade, em nome da proteção da saúde física e psicológica da criança. É neste contexto que surge um conjunto de dispositivos e iniciativas destinadas à educação para a maternidade, ou seja, que as mulheres se tornam o público-alvo de um conjunto de intervenções cujo principal objectivo é assegurar a qualidade das populações, a construção de cidadãos saudáveis e socialmente integrados pela difusão, junto das mães, de normas científicas de criação e educação das crianças.

É de salientar que as estratégias utilizadas no âmbito da educação para a maternidade, cujo principal objectivo é tornar todas as mães, como afirma Maria Manuela Ferreira (2000, p. 132) "mais esclarecidas e conscientes dos seus deveres maternos", possuem um elemento de classe. Enquanto as mulheres das classes populares são alvo de intervenções mais directas, por meio de procedimentos como o inquérito social ou a visitação domiciliária (Apple, 2006; Boltanski, 1977; Ferreira, M. M. 2000), as mulheres oriundas das classes média e média alta vêem os seus comportamentos regulados de uma forma mais indirecta, pela utilização de veículos como os manuais de puericultura, as revistas femininas ou de educação familiar, em que são divulgadas as normas a seguir na criação e educação das crianças, acompanhadas da sua justificação científica, assim como das consequências da sua não aplicação para o desenvolvimento presente e futuro da criança (Apple, 2006; Cahan, 2006; Grant, 1998; Hulbert, 2004; Martins, 2011; Moura; Boarini, 2012; Rose, 1999; Stearns, 2003).

Num período de modernização da sociedade portuguesa, as publicações destinadas às mães se constituiram num dispositivo de regulação e normalização dos comportamentos maternais pelos quais se difundiu o discurso dominante sobre a maternidade, ou seja, a ideologia da maternidade científica (Apple, 2006).

No presente trabalho, optámos por analisar os discursos veiculados por um dispositivo específico, as revistas de educação familiar, como o objetivo de contribuir para a compreensão do processo de construção da maternidade científica em Portugal. Neste sentido, analisámos os argumentos utilizados para invocar a necessidade de educar as mães, o tipo de iniciativas divulgadas e, por último, o nível de adesão das mães a este processo.

A opção pelas revistas de educação familiar, e não por qualquer outro tipo de fonte, deve-se, por um lado, ao facto de serem concebidas com a dupla finalidade de educar os pais e regular as práticas educativas no seio da família e, por outro, a um conjunto de características que possuem e que as tornam, na nossa opinião, fontes privilegiadas para a análise dos discursos acerca da maternidade: 1) são mais acessíveis, por comparação com os manuais de puericultura, quer devido ao seu preço, quer à existência de mais variados pontos de venda, abrangendo, por isso, um público mais vasto; 2) são compostas por um conjunto heterogéneo de textos, que permitem aceder, quer ao nível 
macro das concepções de maternidade, ou seja, aos discursos produzidos pelos peritos e por uma elite simbólica, quer ao nível micro, o da experiência concreta das mulheres que para aí escrevem, o que permite o acesso a vozes que de que outra forma não seriam ouvidas no espaço público (Nóvoa, 1997; Pessoa, 2005).

A selecção das fontes utilizadas foi realizada com base no Repertório analítico da imprensa de educação e ensino (Nóvoa, 1993), de acordo com os seguintes critérios: 1) pertencer à subcategoria educação familiar; 2) ser publicada ao longo de todo o intervalo de tempo estudado. Foram assim seleccionadas as seguintes revistas: Os nossos filhos (1942-1964) e Saúde e lar (1944-1987). No que diz respeito ao corpus documental, este foi constituído por 628 textos (Os nossos filhos, n=475; Saúde e lar, n=153), que foram sujeitos a uma análise de conteúdo qualitativa (Mayring, 2004). Na realização desta análise, cujos resultados passaremos a apresentar, foram utilizadas as seguintes categorias: 1) argumentos utilizados para invocar a necessidade de educar as mães; 2) estratégias de educação para a maternidade; 3) adesão à ideologia da maternidade científica. Estas categorias foram formuladas a priori com base nos objetivos anteriormente enunciados.

\section{Educar as mães sob a orientação da ciência}

As revistas de educação familiar publicadas no Portugal do pós Segunda Guerra Mundial constituíram um veículo de circulação de um discurso produzido por diferentes atores - médicos, educadores, jornalistas, escritores, mulheres letradas - que tinham como objetivo comum à proteção da infância. Defensores de uma concepção tradicional de família, em que à mulher era atribuída a esfera doméstica, e crentes no papel que a ciência, designadamente a Medicina, poderia desempenhar na resolução dos problemas que afetavam as crianças portuguesas, os colaboradores das revistas analisadas difundem um discurso em que uma conceção tradicional de família se cruzava com uma conceção moderna de educação, no sentido em que se entendia que esta devia ter por base o conhecimento científico acerca da criança.

Uma ideia unânime entre aqueles que escrevem nas revistas, reveladora de uma concepção tradicional do papel da mulher no seio da família, é a de que a criação e educação dos filhos seria responsabilidade feminina, mais concretamente da mãe. Esta concepção é reforçada nos discursos acerca da geração, criação e educação das crianças, ou, mais concretamente, no perfil de boa mãe que lhes está subjacente e do qual faz parte a ideia de que as mães se deviam ocupar pessoalmente de tudo o que dizia respeito aos seus filhos. Mais concretamente, as boas mães, no entender geral desse tempo, são aquelas que "pesam as crianças, medem-nas, espreitam-lhes os catarros e a regularidade do ventre, notam-Ihes a cor das faces" (Mira, 1945, p. 6), que vigiam a sua saúde, que se transformam em mãezinhas enfermeiras quando as crianças adoecem, que tratam do vestuário, da higiene e da alimentação, que as orientam nas actividades do quotidiano, que as preparam para a escola primária, ou seja, que se dedicam de corpo e alma à criação e educação das crianças. Neste contexto, a função maternal é valorizada e o papel que a mãe pode desempenhar na garantia da saúde física e mental dos seus filhos é enfatizado.

A valorização do papel da mãe na criação e educação dos filhos é acompanhada, paradoxalmente, pela constatação da sua incapacidade para desempenhar de forma 
eficaz esta tarefa. É de salientar, nos discursos sobre a incapacidade das mães, o que designamos de universalização, fenómeno já identificado por Vilhena (2002) na análise de um conjunto de periódicos de educação e ensino publicados nos anos 1940, em Portugal, no sentido em que é apresentada como um problema que se estendia às mulheres de todas as classes sociais, como é visível no texto que a seguir reproduzimos:

Porque de tanta protecção necessitam os inocentes que não têm lar, nem pão, nem mãe - como aqueles que, nascidos em berços de oiro, se criam abandonados por mães frívolas e inconscientes, entregues a criadas ignorantes; ou são, pelas próprias mães, pessimamente deseducados. (Conselhos, 1947, p. 24)

Embora uma grande maioria das mulheres seja considerada incapaz de criar os seus filhos, os autores que escreviam nas revistas analisadas referem diferentes tipos de incapacidade, marcados pela classe social de pertença das mulheres. Enquanto em relação às mães das classes populares é referida a sua ignorância (Carvalho, 1946; D’Almada, 1951b; Esteves, 1946), as mães das classes mais favorecidas, embora também muitas vezes apelidadas de ignorantes, são, sobretudo, criticadas pela negligência (Mães, 1946; Paço, 1946), ou seja, pelo abandono a que votavam os seus filhos, entregando-as a criadas, mulheres do povo que não possuíam os conhecimentos adequados para bem criar e educar as crianças.

Um aspeto comum a estes discursos, independentemente de se centrarem na ignorância ou na negligência das mães, é a responsabilização destas pelos problemas que afetam as crianças. Como afirma o médico Guido Cabral (1948, p. 20), referindo-se à mortalidade infantil, uma das questões que mais preocupava as elites da época,

a mortalidade infantil é devida a três causas primordiais: enterite $(40 \%)$, debilidade congénita $(20 \%)$ e doenças broncopulmonares $(20 \%)$ [...]. A maior parte destes casos de mortalidade infantil é devida à ignorância das mães e de outras pessoas que cuidam das crianças, pois estas não têm o entendimento necessário para saberem e procurarem o que melhor thes convém.

Contatando diariamente com as mães e com as crianças, nos seus consultórios ou nos serviços em que trabalhavam, os médicos, principais autores dos discursos em que se estabelece uma ligação entre a ignorância das mães e os problemas da infância, a que não será alheio o facto de se percepcionarem como o "único corpo profissional com formação para uma intervenção científica sobre a criança" (Ferreira, 2003, p. 14), conscientes de que muitos dos problemas com que se deparavam quotidianamente eram evitáveis, não podiam deixar de se chocar com as altas taxas de mortalidade e morbilidade infantis que, apesar de terem diminuído no período pós Segunda Guerra Mundial, colocavam ainda o país na cauda da Europa. É, contudo, de realçar, nestes discursos, as parcas referências às condições sociais em que vivia a maioria das mulheres e crianças portuguesas no período analisado e a ênfase colocada na ignorância das mães como a causa primordial dos problemas que afetavam a infância. Neste contexto, a educação para a maternidade emergia, de uma forma quase natural, como a estratégia privilegiada a utilizar na proteção à infância: 
Bem mais do que os defeitos de assistência, bem mais ainda do que a pobreza ou mesmo que a miséria é a ignorância das mães que causa mais malefícios ao lactante e à criança em geral. A educação das mães será, pois, o meio mais poderoso e seguro para a protecção da infância. (As mães, 1954, p. 17)

Estes discursos fazem parte de uma estratégia mais vasta de transformação das formas de criação e educação das crianças, assente na crença do papel que a ciência poderia desempenhar na solução dos problemas da infância. Claro, a Medicina tinha já uma longa tradição e sentia-se especialmente vocacionada a liderar os contributos para o bem-estar das crianças e para o progresso da sociedade:

A medicina tem conseguido vencer nos últimos anos numerosas doenças que eram de grande mortalidade de crianças quer na primeira infância quer recém-nascidas. Do mesmo modo devido aos conhecimentos que possuímos hoje sobre a repercussão que os traumatismos, sofridos pela mãe, podem ter no desenvolvimento da criança deu-se a este assunto a devida importância protegendo-se a mãe que trabalha, o que trouxe grandes benefícios às últimas gerações. (Defeitos, 1956, p. 2)

Mais concretamente, o que se procurava era a generalização de um modelo de maternidade assente numa racionalidade científica. Pretendia-se, assim, que as prescrições pedagógicas reproduzidas pelos colaboradores das revistas de educação familiar fossem, como defende Maria Manuela Ferreira (2000), apropriadas pelo sensocomum, contribuindo-se, desta forma, para a transformação da mãe tradicional, cujas práticas educativas eram fruto do acaso ou da tradição, numa mãe moderna, que tentava aplicar quotidianamente os mais recentes conhecimentos científicos sobre 0 desenvolvimento físico e psicológico da criança, em nome do bem estar presente e futuro do seu filho, mas também da Nação. Como afirma o médico Gilberto Vasco (1945, p. 3),

preconceitos, crendices, e outros erros [...] bem como a razão dos seus prejuízos, deverão desaparecer da linguagem do nosso povo, como o auxílio de todos, e, em particular, daqueles que me compreendem. Frisemos que às mães devem interessar, acima de tudo, a saúde e o bemestar do seu filho, assim como todos os cuidados que contribuam para torná-lo um cidadão válido e eficiente.

Os colaboradores das revistas de educação familiar participaram ativamente neste processo de construção da maternidade científica, não só pela publicação dos princípios científicos de criação e educação das crianças, sob a forma de conselhos, mas também pela divulgação de outras iniciativas e estratégias pedagógicas concebidas com a finalidade de difundir e generalizar esta nova conceção de maternidade. Gostaríamos de salientar que nesta campanha em prol da difusão da maternidade científica se envolveram homens e mulheres de diferentes quadrantes políticos e sociais, peritos e não peritos, pertencentes a uma elite urbana, letrada, que, tendo como denominador comum a proteção à infância, utilizaram as revistas de educação familiar como instrumento de disseminação das suas ideias, cooperando assim para uma mesma finalidade, a educação para a maternidade, em nome do progresso e da modernização da sociedade portuguesa. 


\section{A formação da mãe}

Embora o discurso sobre a necessidade da educação para a maternidade tenha um caráter universal, uma vez que tem como público-alvo todas as mulheres, nas estratégias educativas concebidas para educar as mães é visível um elemento de classe, o que vai ao encontro de resultados obtidos por vários autores que estudaram esta temática (Apple, 2006; Grant, 1998; Ferreira, M. M. 2000). Enquanto as mães das classes populares eram alvo de intervenções mais diretas, tais como as conferências realizadas no seio das instituições de assistência à maternidade e à infância, as mães das classes mais favorecidas viam o seu comportamento regulado de uma forma indireta.

Para as mulheres alfabetizadas, pertencentes à classe média ou alta, que constituíam uma minoria da população feminina portuguesa nesta época, a estratégia utilizada era a persuasão para a auto-educação, ou seja, para a aquisição voluntária de conhecimentos científicos acerca da criação e educação das crianças pela realização de cursos, de leituras ou da consulta a peritos.

O recurso às leituras para este efeito não é um fenómeno novo, como demonstra António Gomes Ferreira (2000) no seu trabalho acerca da criação e educação das crianças no Antigo Regime. $O$ que se assiste no período em análise é a uma diversificação das estratégias educativas - cursos de educação para a maternidade, programas radiofónicos e, mais tarde, televisivos, acerca da criação e educação das crianças - a par com uma crítica mais cerrada ao recurso ao aconselhamento informal, em que se alertava para 0 risco inerente às práticas educativas tradicionais $e$, simultaneamente, se salientavam os benefícios oriundos da adoção de práticas fundadas na razão. A crítica generalizada ao aconselhamento informal é ainda acompanhada pela referência às fontes de aconselhamento consideradas seguras - profissionais de saúde, médicos e enfermeiras, livros e revistas -, cujo saber tinha por base o conhecimento científico, designadamente aquele oriundo da medicina e da psicologia infantil, ciências centrais na construção da maternidade científica.

Os livros, assim como as revistas de educação familiar, eram considerados elementos essenciais no processo de auto-educação da mãe moderna, por possuírem a vantagem de poderem ser acedidos sempre que a mulher considerasse necessária a sua consulta: "Este bebé despertou agora, no seu bercinho cor de rosa, é uma criança sadia, bem tratada - feliz. [...] a Mãe, que não possui nenhuma preparação especial, teve o bom senso de comprar e ler os melhores livros de puericultura, cujos conselhos segue diariamente" (O menino, 1945, p. 15).

São frequentes as referências, nas revistas analisadas, a livros escritos por médicos e pedagogos, alguns dos quais colaboradores das próprias revistas, dos quais são muitas vezes transcritos excertos, tais como: $O$ guia das mães, escrito pela médica Branca Rumina; Mãe e filho, da autoria do médico Ferreira de Mira; ou Eu quero conhecer o meu filho, de que é autor o médico António Correia. Os livros indicados também nos apresentam uma ideia clara do público a quem estas revistas se destinavam: mulheres instruídas, pertencentes a uma elite urbana, preocupadas não só em assegurar a sobrevivência dos seus filhos, mas também com a sua educação. Um artigo intitulado Bibliografia, cujo excerto a seguir transcrevemos, é especialmente ilustrativo deste aspeto, designadamente se tivermos em conta os títulos recomendados: 
Muitas mães desejam ter conhecimentos pedagógicos seguros, para poderem orientar os seus pequeninos. Algumas pretendem reunir os filhos com os amigos e remediar, assim, a falta de escolas infantis, nas terras ou nos bairros que habitam. Lendo com atenção "Os Nossos Filhos", essas mães encontrarão matéria para se instruírem e orientarem. Hoje vamos indicar-lhes algumas obras cuja leitura lhes será muito útil. Para compreender o ensino infantil, é indispensável conhecer o método Montessori e o método Froebel, do qual aquele deriva. Deve consultar-se: A criança - de Montessori, traduzido em português. Education Montessori de Fisher, adaptado em francês por Jacqueline André. Montessori en action - Edição de Nathan, Paris. Froebel en action - Edição de Nathan, Paris. (Bibliografia, 1952, p. 9)

Estes títulos não só constituem indícios da existência de outro tipo de preocupações, que não se prendiam com o assegurar a sobrevivência das crianças, mas sim com o seu desenvolvimento intelectual, como também são reveladores do que Apple (2006) e Hulbert (2004) denominam de profissionalização da maternidade, facto relacionado com a emergência da maternidade científica e que se traduz no tratamento das mulheres, designadamente aquelas pertencentes às classes mais favorecidas, como especialistas da infância, que deviam conhecer e aplicar quotidianamente os métodos científicos de educação das crianças, alguns deles oriundos das instituições de educação de infância, como é o caso de Montessori ou Froebel.

Para além da indicação dos títulos que as mães deviam ler e da transcrição de excertos dos mesmos, são ainda publicadas pequenas recensões, como é o caso daquela em que se apresenta a obra A higiene, a criança e o conforto do lar, da autoria da médica Custódia do Vale (Sem título, 1945, p. 4). Esta recensão é particularmente interessante porque sugere um conjunto de estratégias educativas destinadas a um grupo social específico, as mulheres do povo:

"A Higiene, a Criança e o conforto do Lar" é um trabalho que interessa
principalmente às mulheres do campo, mas que todas, mesmo as de certa
cultura, lerão com proveito e agrado. A autora escreve simultaneamente
como médica e mulher, queremos dizer: esclarece, aconselha, ensina,
numa linguagem clara e singela que parece brotar mais do coração do que
do cérebro. Só encontramos um senão nesta obra - senão que não lhe
pertence: é que não possa ser lido por todas as mulheres rurais, pela
simples e triste razão de que a maior parte delas não sabe ler. Assim,
recomendamos este livro, vivamente, às professoras e outras senhoras
das aldeias, que o poderão ler e explicar às mães das suas alunas, às
suas caseiras e simples conhecidas do povo. (do Vale, 1945, p. 4)

Este tipo de discurso é produzido, na sua grande maioria, pelas mulheres que escreviam nas revistas de educação familiar, designadamente na revista Os nossos filhos. Pertencentes a uma elite intelectual urbana, o seu objetivo era envolver as suas leitoras na campanha em prol da proteção da infância, na difusão dos princípios modernos de criação e educação das crianças junto daquelas que pela sua ignorância eram consideradas as principais responsáveis pelas tragédias que afetavam a infância e que, pelos locais onde viviam, situados em meio rural, dificilmente teriam acesso aos médicos, principais divulgadores, neste período, das práticas científicas de criação e educação das crianças. 
Estamos, neste caso, perante uma estratégia que podemos classificar como maternalista (Koven; Michael, 1993), no sentido em que não parte do Estado, mas sim de uma elite feminina que, em nome do bem-estar da criança e da sociedade, procura integrar todas as mães numa nova racionalidade, num novo modelo de maternidade pela transformação de um grupo de mulheres, aquelas que aderem à conceção da maternidade científica, em agentes ativos no projeto de modernização da maternidade e da sociedade portuguesa.

Outro dos dispositivos utilizado na difusão da maternidade científica são as instituições de assistência à maternidade e à infância (Grant, 1998; Litt, 2000) dispensários, serviços de puericultura e Centros de Saúde - cuja existência é publicitada nas revistas analisadas (e.g. Atenção, 1952; Uma iniciativa, 1955; D’Almada, 1951a; Rumina, 1948). Num contexto de expansão do modelo médico e num momento em que, no que diz respeito aos cuidados de saúde, se assiste a uma mudança de paradigma, ou seja, como afirma Ferreira (2012), em que a ênfase é colocada não no tratamento, mas sim na prevenção da doença, a ideia é dar uma maior visibilidade ao trabalho desenvolvido e desse modo abrir possibilidades de acompanhamento e de formação das mães, utilizando um conjunto de estratégias persuasivas, entre as quais se encontram a publicitação dos bons resultados obtidos através da ação dessas instituições:

Apesar de tudo sentimos satisfação quando olhamos o caminho percorrido e verificamos que a frequência tem aumentado sempre, e que pela leitura da estatística se vê que a mortalidade infantil por diarreia, em menos de um ano, tem diminuído na área urbana do Funchal, onde actua o Dispensário, e que nas classes mais protegidas já as crianças vão ao médico para apreciar o seu estado, independentemente de qualquer suspeita de doença. (Gouvêa, 1951, julho, p. 16)

A referência, nas revistas analisadas, às instituições de assistência materno-infantil deve-se ao facto de, como afirma Pessoa (2005), relativamente à revista Os nossos filhos, se acreditar que assistência e educação para a maternidade constituíam duas faces da mesma moeda, ou seja, de que eram estratégias complementares nesse grande empreendimento de que as revistas eram apenas mais um recurso, o da proteção da criança portuguesa. Pretendia-se, assim, não só divulgar o trabalho que aí se realizava, mas também persuadir a sociedade civil da importância daquelas instituições e incitar a que particulares participassem ativamente na sua criação, como é visível no primeiro parágrafo do texto em que se apresenta o Centro de Enfermagem Assistência à Maternidade e à Infância, uma instituição particular, criada por iniciativa da pedagoga Sofia Abecassis:

Há em Lisboa uma obra de assistência à Maternidade e à Infância que merece ser conhecida de todo o país e principalmente daqueles que, senhores de grandes fortunas, podem e devem empregar o que thes sobeja em favor de seus irmãos que nada têm. Não queremos dizer com isto organizem obras forçosamente iguais, mas que as realizem com a mesma inteligência e compreensão (Braga, 1947, p. 14)

Para além da instituição acima mencionada, são ainda publicitados, entre outros, o Centro de Saúde de Lisboa e a Fundação Nossa Senhora do Bom Sucesso, instituições 
de referência no Portugal dos anos 1950. Dirigidas, tal como o Centro de Enfermagem Assistência à Maternidade e à Infância, por enfermeiras com formação em Saúde Pública, "formadas, não apenas para cuidar de pessoas doentes, mas sim para ensinar os princípios de higiene" (Ferreira, 2012, p. 16), o trabalho aí realizado tem como principais objetivos a prevenção da doença e a melhoria do estado de saúde da população pela realização da educação sanitária daqueles que as frequentam, designadamente das mães, que seriam instruídas nas modernas regras de criação e educação das crianças pequenas:

O ensino sanitário visa mostrar a importância das condições normais da vida diária, incluindo o ambiente familiar, estabilidade, repouso, alimentação, exercício, ar livre, distracções, condições de saúde. Procura mostrar a importância do exame médico periódico em crianças saudáveis, vacinações, instruções que evitem a propagação de epidemias, prevenção de doenças, despiste precoce de defeitos e anomalias para reabilitação, como proceder em caso de doença, interpretar correctamente as prescrições médicas feitas, ensino do desenvolvimento normal da criança, físico e mental, suas variações, etc. (Atenção, 1952, p. 15)

Neste sentido, um conjunto diversificado de iniciativas com caráter profilático, como a vacinação e a vigilância médica regular do estado de saúde das crianças - "Na sede do Centro [Centro de Enfermagem "Assistência à Maternidade e Infância] efectuam-se duas consultas por semana, para vigilância de crianças sãs e vacinação contra doenças evitáveis (varíola, difteria, febre tifóide, tosse convulsa)" (Braga, 1947, p. 14) -, que permitiriam não só garantir, na medida do possível, o bem-estar da criança, mas também a vigilância e o controlo das mães, seria acompanhado pela realização de diferentes atividades educativas:

O trabalho a realizar de futuro no Centro obedecerá às mesmas directrizes que foram seguidas até agora; mas contamos também inaugurar cursos de puericultura para as mães e pais das crianças vigiadas pelo Centro, que são gratuitos, como ainda outros semelhantes destinados a senhoras que desejem aprender estes assuntos tão úteis, e que terão uma inscrição paga, cuja receita reverte a favor da Obra do Centro. (Braga, 1947, p. 14)

Criadas, inicialmente, para as classes populares, é visível, no período em análise, um esforço no sentido de seduzir novos públicos, com a criação de cursos mais formais, a que não será alheio, possivelmente, o processo anteriormente referido da transformação da ignorância das mães numa categoria universal (Vilhena, 2002), mas também, quer uma crença no efeito benéfico que estas mães poderiam exercer sobre as mulheres das classes populares - "esta modalidade de trabalho ocasiona contacto de pessoas com melhor nível de vida com outras em pior situação, ajudando a educar e a elevar o meio" (Atenção..., 1952, p. 14) -, quer uma preocupação crescente com a prevenção da doença e a melhoria do bem-estar físico e psicológico das crianças:

Este programa [Enfermagem de Saúde Pública] de prevenção da doença, conservação e melhoria dos 'standards' de saúde da Criança constitui, fora de dúvida, um dos maiores progressos da época moderna, directamente ligado à ânsia de uma vida mais cheia, mais feliz e mais saudável. ( $O$ papel, 1953, p. 10) 
Procurava-se, assim, por estas iniciativas, abranger uma população que tradicionalmente não frequentava este tipo de instituições e, simultaneamente, contribuir para a difusão alargada da conceção de maternidade científica. Para além do curso acima referido, cuja abertura é, mais tarde, publicitada em Os nossos filhos (Uma iniciativa, 1955), é também referida a criação, no Centro de Saúde de Lisboa, de um "curso de 6 lições para futuras mães" (O Centro, 1945, p. 12), e de uma Escola de Pais, pelo médico Vítor Fontes, no Instituto António Aurélio da Costa Ferreira, mais direccionada para a promoção da saúde mental (Escola, 1957).

A divulgação da realização destes cursos, a par com a referência às leituras que as mulheres deviam realizar, tem como destinatárias as mulheres de um grupo social específico, aquelas que lêem as revistas, mulheres de classe média, alfabetizadas e que, por esse motivo, se considera ser seu dever educar-se e, mais do que isso, participar ativamente na campanha de disseminação da maternidade científica.

Contudo, o processo de adesão a este modelo de maternidade não é, de forma alguma, pacífico e linear, como demonstram, quer os testemunhos dos colaboradores, quer das próprias mães nas cartas que escrevem para as revistas, que serão objeto de análise no ponto que se segue.

\section{As mães e a educação para a maternidade}

A análise dos discursos das mães que escreviam para as revistas, assim como dos testemunhos daqueles que com elas diariamente conviviam, permite-nos ver, embora tenhamos consciência que de uma forma parcial, o grau de adesão das mulheres à maternidade científica. Mais concretamente, permite-nos detetar resistências, mas também a crença profunda de um grupo minoritário de mulheres, educadas e pertencentes às classes mais favorecidas, no papel que a ciência poderia desempenhar na sobrevivência e na manutenção da saúde, física e psíquica dos seus filhos e que procuravam, por esse motivo, de uma forma autónoma e de livre e espontânea vontade, como refere Apple (2006), o conselho dos peritos.

Nos testemunhos daqueles que conviviam diariamente com as mães, transparece a existência de resistência, por parte das mulheres, designadamente daquelas pertencentes às classes populares, à conceção de maternidade científica. Júlio Esmeraldo Gouvêa (1951, p. 16), director do Dispensário de Higiene Infantil do Funchal, relata as dificuldades sentidas neste processo, assim como a presença de um elemento de classe na adesão a esta conceção de maternidade, que parecia seduzir especialmente as mães das classes mais favorecidas, como já haviam verificado, entre outros autores, Apple (2006), Grant (1998) e Litt (2000). Mas das palavras dele não há mais que a constatação da não compreensão do conceito de saúde preventiva, da instituição de uma medicina de vigilância (Armstrong, 1995), da qual as mulheres não parecem compreender a necessidade. Diz ele:

A dificuldade maior que temos tido é convencer as mães a trazerem ao Dispensário as crianças no dia indicado, para a observação periódica, pois, ainda hoje, muitas faltam, alegando que a criança não estava doente, no dia indicado, visto as mães menos esclarecidas não compreenderem que se deva levar o filho ao Dispensário, quando tem saúde, e só com o fim de evitar que venha a adoecer. (Gouvêa, 1951, p.16) 
Para os médicos ou pessoas fortemente impregnadas pelos saberes da Medicina e da Psicologia, todos aqueles que não atendiam às suas orientações eram ignorantes ou negligentes. Em geral, dos seus discursos não se evidencia consciência das dificuldades que a maior parte da população tinha que enfrentar, algumas delas inerentes à precariedade da sua vida material. Muitas das mães que caracterizavam o universo das mulheres acusadas de ignorantes pelos médicos tinham vidas centradas na preocupação com a sobrevivência dos que delas dependiam. Esta situação, conjugada com as baixas taxas de escolarização das mulheres portuguesas no período em análise e com a dificuldade de acesso aos cuidados de saúde, tinha que condicionar bastante a adesão a ideias e a práticas que associamos à conceção de maternidade científica.

A questão da adesão a práticas provenientes de conhecimentos legitimados pelas racionalidades médicas e psicológicas não era tão só uma questão de vontade das mães, como se tendia a passar nos discursos difundidos pelos peritos ou pelos que difundiam os seus saberes. É evidente que os que escreviam para as revistas analisadas não compreendiam bem os problemas de parte da população que não correspondia às suas ideias, às suas orientações. Contudo, isto não significa que não existissem pessoas que não reportassem obstáculos à disseminação de práticas condizentes com o moderno pensamento científico.

A dificuldade de acesso aos médicos e aos cuidados de saúde é um dos obstáculos referido quer pelos autores - "Há, é certo, bastantes postos de puericultura na cidade [Lisboa] e no país, mas o seu número é ainda insuficiente, as vagas muito diminutas em relação à população infantil" (Braga, 1947, p. 14) - quer pelas mães que escreviam para as revistas, sobretudo aquelas que residiam no meio rural - "Vivo numa herdade e só tenho Médico e farmácia a léguas de distância" (Sem título, 1950, p. 10). A dificuldade de contato com os médicos, ponto de acesso direto ao conhecimento científico, poderá ter contribuído para a resistência ou, inclusivamente, para o desconhecimento da conceção de maternidade científica, designadamente por parte das mulheres das classes populares que não tendo acesso às revistas ou livros dificilmente conseguiriam aceder a esta nova racionalidade.

Contudo este não é único factor que explica a resistência, da parte de algumas mulheres, ao ideal de maternidade científica. De acordo com o médico Constantino Esteves (1946, p. 10), o contato com os especialistas não constituía garantia de cumprimento das prescrições por eles ditadas. Nas palavras deste clínico existia claramente "ignorância - para não empregar epíteto mais rude - quando é de todos os dias a não observância das prescrições médicas e a sua substituição por outras que se julgam mais abalizadas". Por outras palavras, o acesso ao conhecimento científico sobre a criação e educação das crianças não constituiu, de modo nenhum, condição suficiente para que as mulheres aderissem à conceção de maternidade científica, uma vez que o elevado número de vezes em que é referido o recurso ao aconselhamento informal, assim como a veemência com que é criticado, leva-nos a presumir que esta era uma prática relativamente frequente, ou seja, que muitas mulheres continuavam a recorrer e a confiar, sobretudo, no saber tradicional transmitido pelo familiares, pelas vizinhas e pelas comadres. Tal poderá ser explicado pelo facto das mulheres pertences às classes populares, na sua grande maioria analfabetas, não terem sido socializadas no respeito 
pelo conhecimento técnico, processo que se efectua, sobretudo, pela educação formal (Boltanski, 1977; Giddens, 2005).

Relativamente às mães das classes mais favorecidas, podemos observar a existência de dois movimentos: enquanto algumas mães, alvo frequente de críticas, se demitiam da função maternal, deixando as crianças entregues às criadas - "Para a grande maioria, os filhos só merecem atenção dos sete anos em diante; até esta data encarregam-se deles as criadas" (Correia, 1949, p. 6) - não aderindo ao perfil de boa mãe esboçado pelos peritos, outras aderiram à concepção de maternidade científica procurando educar-se e, mais do que isso, a participar ativamente nesta campanha em prol da infância, colaborando para a reeducação das mulheres que com elas conviviam.

Classificando-se como ignorantes, ou seja, interiorizando o discurso produzido pelos autores, as mães que escreviam para as revistas invocavam o desejo de se educar, de aderir ao modelo de maternidade proposto. Tal é visível na solicitação de orientações sobre qual o comportamento a adoptar nas mais variadas situações: "Tenho ouvido dizer que não se devem cortar as unhas às crianças. Peço-lhe que me dê a sua opinião" (Lídia, 1947, p. 24); "Minha filha, que fez agora precisamente 3 anos, tem um génio terrível, é caprichosa e teimosa. Como devo dominá-la?" (Sem título, 1953, p. 7); "Estou à espera do meu primeiro filho. Peço-lhe que me indique alguns livros de puericultura para me instruir" (Sem título, 1947, p. 24). Pedidos de conselhos como este último indiciam mais do que uma adesão superficial à maternidade científica. Eles remetem para uma preocupação pedagógica, para uma vontade de buscarem a informação adequada a uma mãe moderna e esclarecida. É esse o caso de uma mãe que escreve: "O meu filho é bem proporcionado e tem saúde, mas acho-o extremamente pequeno, o que me causa grande desgosto. Peço que publique uma tabela de estatura, e diga com que intervalo de tempo e de que maneira se devem medir as crianças" (Sem título, 1948, p. 11).

Crentes no papel que a ciência poderia desempenhar na promoção da saúde e na garantia da normalidade do desenvolvimento dos seus filhos, estas mulheres procuravam, ativamente, informação sobre aquelas que acreditam ser as melhores práticas para criar e educar as crianças.

Estas revistas suscitam, como temos visto, certa mobilização. Elas pretendem que as leitoras amplifiquem as informações nelas publicadas. Uma forma de o fazer era pela atribuição de um papel ativo às mães, transformando-as em divulgadoras dos princípios subjacentes à conceção de maternidade científica. Tal é visível, por exemplo, na campanha promovida pela revista Os nossos filhos, intitulada Minha senhora, ajude-nos!, em que se apelava às mães para procederem quotidianamente à educação daqueles que com que diariamente se cruzavam: "Não tenha vergonha se ensinar os que não sabem. $\mathrm{Na}$ rua, no comboio ou no eléctrico, em qualquer parte, quando veja alguém proceder mal para com uma criança [...] porque não há-de acercar-se e intervir delicadamente?" (Minha senhora, 1950, p. 11).

As leitoras das revistas, mulheres letradas, mas anónimas, eram, assim, incitadas a passarem de meras figurantes a protagonistas na campanha a favor da difusão da conceção de maternidade científica, colaborando ativamente, a par com os peritos, na campanha em prol da proteção da criança e da modernização da sociedade portuguesa. 


\section{Conclusão}

O presente estudo permitiu verificar que um dos principais objectivos dos editores e colaboradores das revistas de educação familiar era a difusão da conceção de maternidade científica (Apple, 2006).

A divulgação da ideia de que ser uma mãe era uma função que exigia uma preparação especial, a submissão a um processo educativo fundado na razão e na ciência é acompanhada da transmissão de uma visão tradicional da família, conforme à ética familiar dominante no período em análise (Cova; Pinto, 1997; Pimentel, 2011; Rocha; Ferreira, 2006), que tinha subjacente a ideia de que a mãe deveria ser a principal responsável pela criação e educação das crianças.

A responsabilização das mães pela criação e educação dos seus filhos é acompanhada por dois discursos, aparentemente contraditórios. Se, por um lado, a função maternal é valorizada, por outro, as mães são caraterizadas como ignorantes ou negligentes e, consequentemente, como incapazes de, por si só, desempenharem o seu papel da forma que se considerava, no discurso desse tempo, como a mais adequada. Como referem vários autores (Apple, 2006; Armstrong, 1995, Ferreira, M. M. 2000; Rose, 1999; Stearns, 2003), a ênfase na incapacidade das mães é um argumento justificador da intervenção dos peritos na regulação dos comportamentos maternais, utilizado para persuadir as mães de que para bem criar e educar os seus filhos, teriam que se educar, que conhecer os princípios científicos de criação e educação das crianças, divulgados não só pelas revistas de educação familiar, mas também de outros dispositivos - e.g. manuais de puericultura, instituições de assistência materno-infantil, cursos de educação para a maternidade - publicitados nas suas páginas.

Crentes no papel que a educação para a maternidade, elemento essencial da maternidade científica, poderia desempenhar na resolução dos principais problemas que atingem as crianças que viviam, nos anos 1950, em Portugal, os colaboradores das revistas analisadas - médicos, enfermeiras, educadores, jornalistas, escritores -, mas também algumas das suas leitoras, procuram, assim, participar ativamente, em nome da proteção à infância e da modernização da sociedade portuguesa, na campanha de difusão da conceção de maternidade científica (Apple, 2006), pela crítica às práticas educativas fundadas na tradição, transmitidas por aconselhamento informal e pela indicação das fontes que as mulheres deveriam utilizar para colmatarem a sua ignorância e desenvolverem os conhecimentos científicos necessários para bem criar e educar os seus filhos.

A análise dos discursos veiculados pelas revistas de educação familiar tornou ainda evidente a presença de um elemento de classe, visível na existência de estratégias de educação para a maternidade diferenciadas de acordo com a posição social da mulher, aspeto já identificado noutros estudos realizados sobre esta temática (Apple, 2006; Grant, 1998; Ferreira, M. M. 2000). As estratégias difundidas pelas revistas incluíam, para além da leitura das mesmas, o recurso à manuais de puericultura ou a frequência de cursos de educação para a maternidade, que permitiriam não só a auto-educação das leitoras, mas também que estas, conhecedoras dos princípios científicos de criação e educação das crianças, participassem ativamente na disseminação da conceção de maternidade científica. 
Devido à alta taxa de analfabetismo entre as mulheres portuguesas no período em análise, assim como às condições materiais em que viviam, podemos inferir que estas estratégias tinham como grupo alvo uma população muito específica, a mulher de classe média ou média alta, alfabetizada, ou, como afirma Pessoa (2005), a mulher intelectual. É precisamente esta mulher que vai aderir, em primeiro lugar, à conceção de maternidade científica, procurando, ela própria, ativamente, informação que the permitisse criar e educar os seus filhos da melhor forma possível.

\section{Referências}

ADÃO, Áurea; REMÉDIOS, Maria José. The educational narrativity in the first period of Oliveira Salazar's government: women's voices in the National Assembly (1935-1945). History of Education, v. 34, n. 5, 2005, p. 547-559.

ALLEN, Ann Taylor. Feminism and motherhood in western europe 1890-1970. New York: Palgrave Macmillan Press, 2005.

AS MÃES e a assistência a seus filhos. Saúde e Lar, Lisboa, n. 78, abr. 1954, p. 17.

ATENÇÃO ao Centro de Enfermagem: assistência à maternidade e à infância. Os nossos filhos, Lisboa, n. 127, dez. 1952, p. 14-15.

BIBLIOGRAFIA. Os nossos filhos, Lisboa, n. 121, jun. 1952, p. 9.

APPLE, Rima D. Perfect motherhood: science and childrearing in America. New Brunswick, NJ: Rutgers University Press, 2006.

ARMSTRONG, David. The rise of surveillance medicine. Sociology of Health \& Illness, v. 17, n. 3, 1995, p. 393-404.

ARNUP, Katherine. Education for motherhood: advice for mothers in twentieth-century Canada. Toronto: University of Toronto Press, 1994.

BOLTANSKI, Luc. Prime éducation et morale de classe. Paris: Ehess, 1977.

BRAGA, J. M. Uma obra de assistência modelar: o Centro de Enfermagem. Os nossos filhos, Lisboa, n. 60, maio, 1947, p. 14-16.

CABRAL, Guido. V. Ex. ${ }^{a}$ já sabe que... se já sabia, não é demais repeti-lo! Saúde e Lar, Lisboa, n. 37, set., 1948, p. 20.

CAHAN, Emily D. Toward a socially relevant science: Notes on the history of child development research. In: BEATTY, Barbara; CAHAN, Emily D; GRANT, Julia (ed.). When science encounters the child: education, parenting and child welfare in the 20th-century America. New York: Teachers College Press, 2006, p. 16-34.

CANDEIAS, António. Modernidade, educação, criação de riqueza e legitimação política nos séculos 19 e 20 em Portugal. Análise Social, Lisboa, n. 176, 2005. Disponível em: $<$ http://www.scielo.gpeari.mctes.pt/scielo.php?script=sci arttext\&pid=S0003-25732005000 400001\&lng=pt\&nrm=iso >. Acesso em: 7 fev., 2011.

CARVALHO, Liberdade. É preciso auxiliar e instruir a mãe rural. Os nossos filhos, Lisboa, n. 53 , out., 1946, p. 14.

CONSELHOS da avozinha: Da vida e das pessoas. Os nossos filhos, Lisboa, n. 64, set., 1947, p. 24.

CORREIA, Maria Natividade Pinto. Dos 3 aos 6 anos. Os nossos filhos, Lisboa, n. 87, ago., 1949, p. 6. 
COVA, Anne; PINTO, António Costa. O salazarismo e as mulheres: uma abordagem comparativa. Penélope, n. 17, 1997, p. 71-94.

D’ALMADA, Beatriz. Entrevista: Dr. Esmeraldo Gouvêa - O Dispensário de Higiene Infantil do Funchal. Os nossos filhos, Lisboa, n. 110, jul. 1951, p. 14-15.

D’ALMADA, Beatriz. Aqui, Funchal: história verdadeira. Os nossos filhos, Lisboa, n. 114, nov., 1951, p. 14-15.

DEFEITOS congénitos. Saúde e Lar, Lisboa, n. 102, abr., 1956, p. 2.

ESCOLA de pais. Os Nossos Filhos, Lisboa, n. 180, maio, 1957, p. 5.

ESTEVES, Constantino. O papel maléfico da vizinha. Saúde e Lar, Lisboa, n. 25, set., 1946, p. 10.

FERREIRA, António Gomes. Gerar, criar, educar: a criança no Portugal do Antigo Regime. Coimbra: Quarteto, 2000.

FERREIRA, António Gomes. Higiene e controlo médico da infância e da escola. Cadernos Cedes, Campinas, v. 23, n. 59, 2003. Disponível em: <http://www.scielo.br/scielo. php?script=sci arttext\&pid=S0101-32622003000100002\&lng=en\&nrm=iso>. Acesso em: 12 dez., 2012.

FERREIRA, Maria Manuela. Salvar os corpos, forjar a razão: contributo para uma análise crítica da criança e da infância como construção social 1880-1940. Lisboa: Instituto de Inovação Educacional, 2000.

FERREIRA, Óscar Ramos. História da Escola Técnica de Enfermeiras (1940-1968). Lisboa: UL, 2012. 487f. Tese (doutorado em Educação). Instituto de Educação, Universidade de Lisboa.

GIDDENS, Anthony. As consequências da modernidade. Oeiras: Celta, 2005.

GOUVÊA, Júlio Esmeraldo. A acção social do Dispensário de Higiene Infantil do Funchal. Os nossos filhos, Lisboa, n. 110, jul., 1951, p. 16.

GRANT, Julia. Raising baby by the book: the education of American mothers. New Haven: Yale University Press, 1998.

HULBERT, Ann. Raising America: experts, parents and a century of advice about children. New York: Vintage Books, 2004.

KOVEN, Seth; MICHEL, Sonya. Introduction: mothers worlds. In: KOVEN, Seth; MICHEL, Sonya (orgs.). Mothers of a new world: maternalistic politics and the origins of welfare states. New York: Routledge, 1993, 1-42.

LÍDIA. Sem título. Os nossos filhos, Lisboa, n. 58, mar., 1947, p. 24.

LITT, Jacquelyn S. Medicalized motherhood: perspectives from the lives of AfricanAmerican and Jewish women. New Brunswick, NJ: Rutgers University Press, 2000.

MÃES imprevidentes! Os vossos filhinhos correm grandes perigos! Os nossos filhos, Lisboa, n. 51, ago., 1946, p. 25.

MARTINS, Ana Paula. Género e assistência: considerações histórico-conceituais sobre práticas e políticas assistenciais. História, Ciência, Saúde - Manguinhos, Rio de Janeiro, v. 18, n. 1, dez., 2011. Disponível em: <http://www.scielo.br/scielo.php?script=sci arttext\&pid=S0104-59702011000500002\&Ing=en\&nrm=iso>. Acesso em: 21 fev., 2013.

MAYRING, Philipp. Qualitative content analysis. In: FLICK, Uwe; KARDORF, Ernst von; STEINKE, Ines (org.). A companion to qualitative research. London: Sage, 2004, p. 266269. 
MINHA SENHORA, ajude-nos! Os nossos filhos, Lisboa, n. 99, ago., 1950, p. 11.

MIRA, Ferreira de. Criar e educar. Os nossos filhos, Lisboa, n. 32, jan., 1945, p. 6-7.

MOURA, Renata Heller de; BOARINI, Maria Lucia. A saúde da família sob as lentes da higiene mental. História, Ciências, Saúde - Manguinhos, Rio de Janeiro, vol. 19, n. 1, 2012. Disponível em: <http://www.scielo.br/scielo.php? Script=sci arttext\&pid=S010459702012000100012\&lng=en\&nrm=iso>. Acesso: 21 fev., 2013.

NÓVOA, António. A educação nacional. In: MARQUES, António Oliveira; SERRÃO, Joel; ROSAS, Fernando (orgs.). Nova história de Portugal. Vol. XII - Portugal e o Estado-Novo (1930-1960). Lisboa: Presença, 1992, p. 455-519.

NÓVOA, António. A imprensa de educação e de ensino: repertório analítico (séculos $19 \mathrm{e}$ 20). Lisboa: Instituto de Inovação Educacional, 1993.

NÓVOA, António. A imprensa de educação e ensino: concepção e organização do repertório português. In: CATANI, Denice Bárbara; BASTOS, Maria Helena Camara (orgs.). A educação em revista: a imprensa periódica e a história da educação. São Paulo: Escrituras, 1997, p. 11-31.

O CENTRO de Saúde de Lisboa. Os nossos filhos, Lisboa, n. 36, maio, 1945, p. 12-13.

O MENINO dorme. Os nossos filhos, Lisboa, n. 36, maio, 1945, p. 15.

O PAPEL da enfermeira de pediatria e a sua preparação. Os nossos filhos, Lisboa, $\mathrm{n}$. 138, nov., 1953, p. 10.

ODLAND, Sarah Burke. Unassailable motherhood, ambivalent domesticity: the construction of maternal identity in Ladies' Home Journal in 1946. Journal of Communication Inquiry, v. 34, n. 1, 2009, p. 61-84.

PAÇO, Maria João Lopes do. Acorde, mãezinha! Os nossos filhos, Lisboa, n. 45, fev., 1946, p. 14-15.

PESSOA, Ana Maria. A educação das mulheres e das crianças no Estado Novo: a proposta de Maria Lúcia Vassalo Namorado. Lisboa: UL, 2005. 1748f. Tese (doutorado em Ciências da Educação). Faculdade de Psicologia e Ciências da Educação, Universidade de Lisboa.

PIMENTEL, Irene Flunser. A assistência social e familiar do Estado Novo nos anos $30 \mathrm{e}$ 40. Análise Social, Lisboa, v. 34, n. 151/152, 1999, p. 477-508.

PIMENTEL, Irene Flunser. A cada um o seu lugar: a política feminina do Estado Novo. Lisboa: Círculo de Leitores/Temas \& Debates, 2011.

ROCHA, Cristina; FERREIRA, Maria Manuela. As mulheres e a cidadania: as mulheres e o trabalho na esfera pública e na esfera doméstica. Lisboa: Livros Horizonte, 2006.

ROSAS, Fernando. O salazarismo e o homem novo: ensaio sobre o Estado Novo e a questão do totalitarismo. Análise Social, Lisboa, v. 35, n. 157, 2001, p. 1031-1054.

ROSE, Nikolas. Governing the soul: the shaping of the private self. London: Free Association Books, 1999.

RUMINA, Branca. Em Madrid: a obra de puericultura Carmem Franco. Os nossos filhos, Lisboa, n. 68, jan., 1948, p. 16-17.

SEM TÍTULO [recensão do livro A higiene, a criança e o conforto do lar]. Os nossos filhos, Lisboa, n. 42, nov., 1945, p. 4-5.

SEM TíTULO [carta ao editor]. Os nossos filhos, Lisboa, n. 58, mar., 1947, p. 24. 
SEM TíTULO. Os nossos filhos, Lisboa, n. 68, jan., 1948, p. 11.

SEM TÍTULO [carta ao editor]. Os nossos filhos, Lisboa, n. 101, out., 1950, p. 10.

SEM TíTULO [carta ao editor]. Os nossos filhos, Lisboa, n. 138, nov., 1953, p. 7.

STEARNS, Peter. Anxious parents: a history of modern childrearing in America. New York: New York University Press, 2003.

UMA INICIATIVA para si: Como cuidar da criança pequena. Os nossos filhos, Lisboa, n. 154, mar. 1955, p. 7.

VALÉRIO, Nuno (org.). Estatísticas históricas portuguesas. Lisboa: Instituto Nacional de Estatística, 2001.

VASCO, Gilberto Branco. O que se não deve fazer. Saúde e Lar, Lisboa, n. 16, mar., 1945, p. 2-3.

VILHENA, Carla. Institucionalização da educação pré-escolar em Portugal (1880-1950). Lisboa: UL, 2002. 18 f. Dissertação (mestrado em Ciências da Educação). Faculdade de Psicologia e de Ciências da Educação, Universidade de Lisboa.

WAGNER, Peter. A sociology of modernity: liberty and discipline. London: Routledge, 1998.

CARLA CARDOSO VILHENA é professora auxiliar da Faculdade de Ciências Humanas e Sociais da Universidade do Algarve e investigadora do Grupo de Políticas e Dinâmicas Educacionais do Ceis 20. Doutorada em Ciências da Educação pela Faculdade de Ciências Sociais e Humanas da Universidade Nova de Lisboa.

Endereço: Faculdade de Ciências Humanas e Sociais, Universidade do Algarve Campus de Gambelas, 8000-139 - Faro - Portugal.

E-mail: cvilhena@ualg.pt.

ANTÓNIO GOMES FERREIRA é subdiretor e professor da Faculdade de Psicologia e Ciências da Educação da Universidade de Coimbra. Coordenador e investigador do Grupo de Políticas e Dinâmicas Educacionais do Ceis 20, Universidade de Coimbra. Coordenador do doutoramento em Ciências da Educação da Universidade de Coimbra.

Endereço: Faculdade de Psicologia e Ciências da Educação da Universidade de Coimbra - Rua do Colégio Novo, 3001-802 - Coimbra - Portugal.

E-mail: antonio@fpce.uc.pt.

Recebido em 31 de janeiro de 2014.

Aceito em 14 de junho de 2014. 